\title{
Structural health monitoring and structural modifications of industrial building subjected to dynamic loading
}

\author{
Robert Soltys ${ }^{1, *}$, Michal Tomko ${ }^{1}$ and Ivo Demjan ${ }^{1}$ \\ ${ }^{1}$ Technical university of Košice, Faculty of Civil Engineering, 04200 Košice, Slovak Republic
}

\begin{abstract}
A complex structural, static and dynamic review of an existing steel ceiling has been realised after two years of service and the completion of subsequent construction work. The construction work involved the reconstruction of a steel structure and structural modifications to the ceiling, which is part of the production hall. The construction work was realised in order to reduce the vibration response of the ceiling. The interior of the steel structure was supplemented by steel structural elements to share the load transfer of automatic washing machines. The structural behaviour of the ceiling was monitored before and after the modification. Accelerations of the ceiling were time-domain-monitored at specific locations. Measured data was transformed to the spectral-domain which is represented by power spectral densities.
\end{abstract}

\section{Introduction}

Vibrations may occur in wide range of applications in civil engineering structures. There is an important point in design of structures whether the response of the structure will be static or dynamic under considered load. Some loads are considered as static, however they produce a dynamic response, which means the dynamic response is negligible when comparing to static load. Another case is, if the response is dynamic, to calculate a quasisteady response, which is usually represented by response multiplier. This calculation is less time consuming when comparing to computation of dynamic response, represented by spectral analysis or time-domain approach. The important issue of dynamic analysis is to consider increased response of the structure, such as higher deflections, higher stress and the influence of fatigue.

A static and dynamic assessment of a load bearing steel ceiling structure is conducted after two years of operation and the completion of subsequent static/construction modifications of a steel production hall functioning as a factory tool room.

*Corresponding author: robert.soltys@ tuke.sk 


\section{Structural characteristic of the building}

From a structural point of view, the steel production hall consists of three-aisles with a floor size consisting of 7 fields of $6 \mathrm{~m} /(10.225 \mathrm{~m}+9.945 \mathrm{~m}+9.730 \mathrm{~m})$.

Frame girders of rolled HEA 340 sections lie across central steel columns consisting of HEA 300 profiles. The girders are anchored to rolled HEA 200 profiles at an axial distance of $2 \mathrm{~m}$ which supports Rannila RAN-85B profiled cladding having a thickness of $0.88 \mathrm{~mm}$, which is covered by a layer of concrete with dispersed reinforcement.

Foundations of the original reinforced concrete skeleton hall consist of foundation footings which are supported by concrete piles. The interior of the indoor spaces are supported by steel columns anchored using steel M36 anchors onto plain concrete footings with an area of $2.0 \mathrm{~m} \times 2.0 \mathrm{~m}$ and a depth of $1.0 \mathrm{~m}$. The footings are placed on a compacted gravel bed with a thickness of $300 \mathrm{~mm}$.

\section{Chronological description of the building purpose}

After renovation works and structural modifications of the steel structure located at a height of $+10.5 \mathrm{~m}$ completed in 2013, the hall was used for two years as a laboratory space designed for testing automatic washing machines. Over the last two years of use the concrete floor developed a number cracks that tended to enlarge over time.

In 2015 a geodetic survey revealed deformations of steel ceiling elements [1]. The geodetic measurements observed a maximum vertical deformation of $22 \mathrm{~mm}$. Permissible vertical deformation is defined in Standard [2] as 1/250 for a $9000 \mathrm{~mm}$ span. In this case, the standard permits a maximum vertical deformation of $36 \mathrm{~mm}$. Structural steel ceiling in II. limit state terms.

The load bearing steel ceiling in terms of limit state assessment of the permissible maximum vertical deformation is satisfied and the steel beam lies in the elastic range.

\section{Monitoring of structural connections}

In order to determine the current state of the ceiling steel structure diagnostics of welded joints and bolted joints were realized in 2015. The diagnostics was primary focused on detection of fatigue cracks of the welds, Fig. 1. The application of magnetic particle method (according to EN 17638) detected discontinuities, weld defects and other undesirable defects. After evaluation of the measured results (according to EN ISO 5817) it was stated [3], the detected defects are related to welding process, but no fatigue cracks were found. The statement [3] recommended to check the welds periodically.
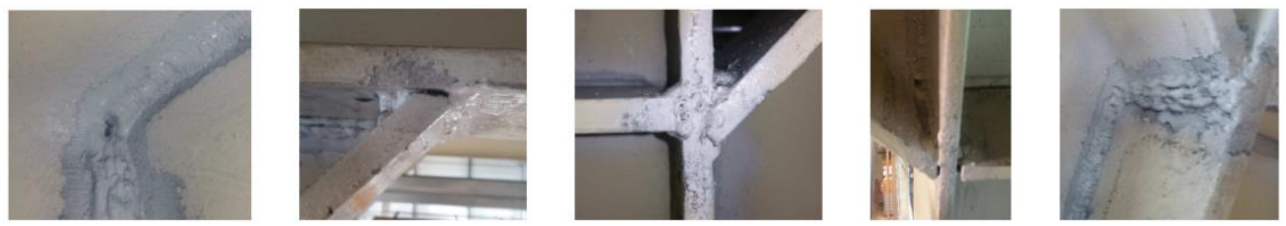

Fig. 1. Discontinuities of some welds observed after the renovation work and completion of structural adjustments of the steel hall structure. 


\section{Vibration tests and measurements}

To comprehend the dynamic behaviour of the steel ceiling structure before the execution of structural modifications (initial state, 2013) and post static/renovation (2015), local experimental vibration measurements were carried out "in situ".

Diagnostic vibration measurements were carried using PULSE instruments and software from Brüel \& Kjær. The vertical direction of acceleration of the ceiling construction was recorded at a sampling frequency of $128 \mathrm{~Hz}$.

\subsection{Dynamic response of the ceiling}

a) time domain log of vibration acceleration

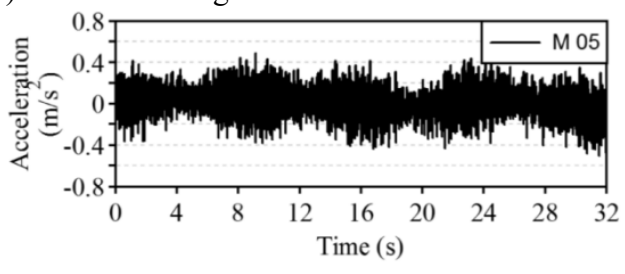

b) power spectral density of acceleration

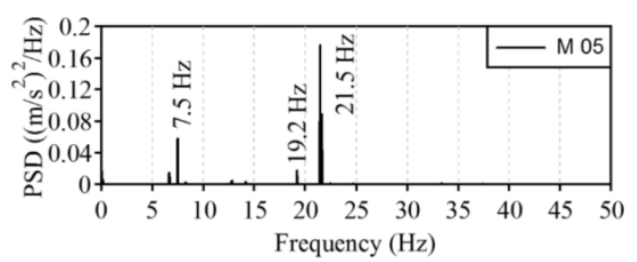

c) power spectral density of acceleration - detail

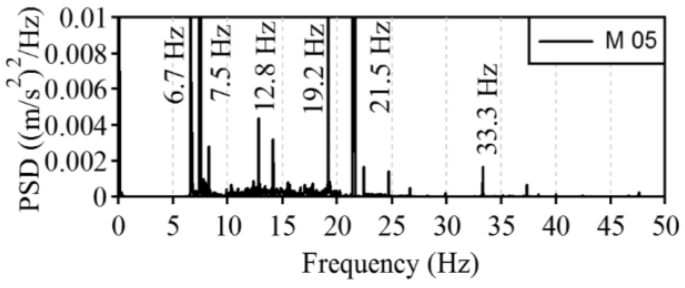

Fig. 2. Measurement 05 (M 05), year 2015.

a) time domain log of vibration acceleration

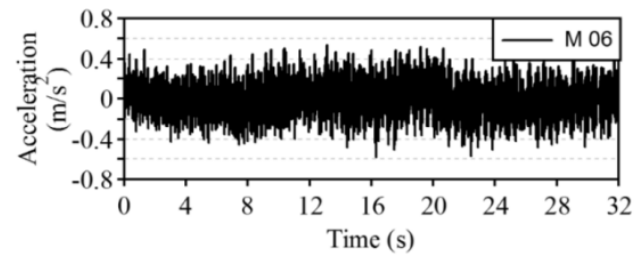

b) power spectral density of acceleration

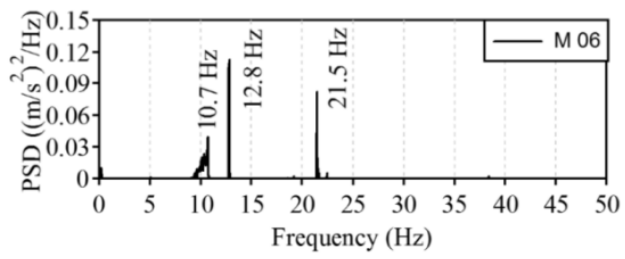

c) power spectral density of acceleration - detail

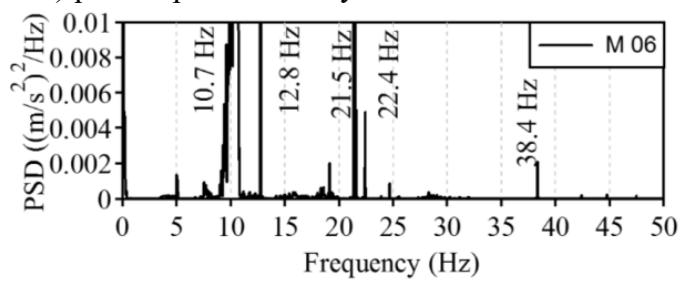

Fig. 3. Measurement 06 (M 06), year 2015.

The results of "in situ" experimental vibration measurements of steel ceiling elements are presented in the form of a time-domain log of vibration acceleration and corresponding power spectral density (PSD), Fig. 2 and Fig. 3. These measurements were recorded at the 
same location, where it was expected the vibration nodal points do not occur. Measurements M05 and M06 represent two datasets recorded at different time with random vibration excitation.

From the attained PSD vibration accelerations it can be assumed, that for power spectral density responses of load bearing steel ceiling constructions the dominant frequency was in the range of $6-13 \mathrm{~Hz}$ and $19-25 \mathrm{~Hz}$.

\section{Analysis of the dynamic response of steel ceiling construction on the basis of theoretical and experimental approaches}

For static and dynamic analysis of the structure, mathematical models of the wall-panel and line elements were created. The computational model contained 6694 nodes, 5600-wall plate elements and 3121 line elements, Fig. 4.

The eigenfrequency and associated mode shapes were obtained using a computational model. Forced vibration was computed using the modal decomposition method and direct numerical integration method, Fig. 5.

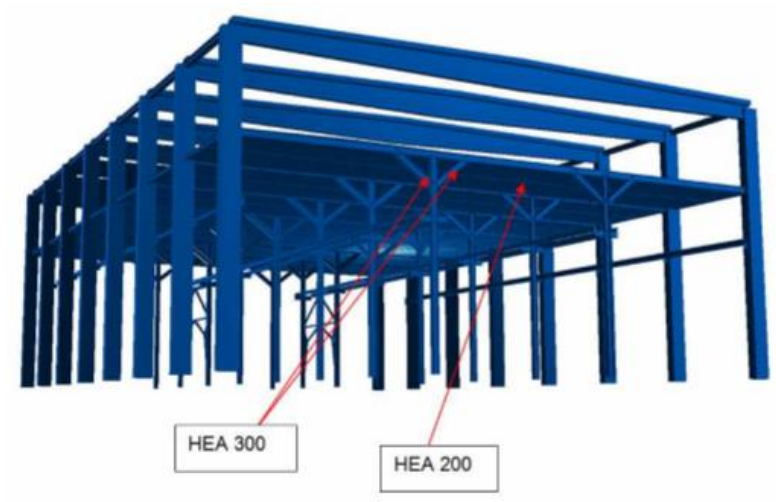

Fig. 4. Rendered static-dynamic diagram of the steel hall structure.

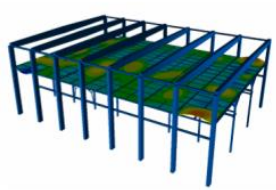

$13.10 \mathrm{~Hz}$

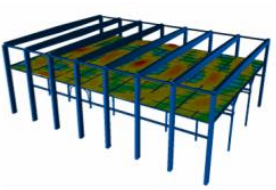

$17.06 \mathrm{~Hz}$

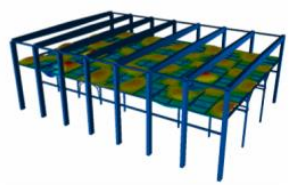

$20.261 \mathrm{~Hz}$

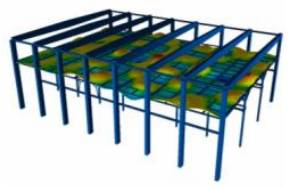

$22.097 \mathrm{~Hz}$

Fig. 5. Selected eigenfrequencies and corresponding shapes of the building structure's computational model.

Forced vibration analysis was performed by the modal decomposition method $[4,5]$. Theoretical computations were monitored for 10 seconds of vibration with a time step of 0.01 seconds. Logarithmic decrement of attenuation was assumed to be 0.1 . Harmonic excitation was simulated with a variable force $F(t)$ defined by $F(t)=F \cdot \sin (\omega t+\phi)$. The amplitude of the harmonic variable force $F(t)$ was assumed to be $0.2 \mathrm{kN}$. The exciting angular vibration frequency $\omega$ was considered for frequencies of $13 \mathrm{~Hz}, 14 \mathrm{~Hz}, 15 \mathrm{~Hz}, 16$ $\mathrm{Hz}, 17 \mathrm{~Hz}, 18 \mathrm{~Hz}, 19 \mathrm{~Hz}, 20 \mathrm{~Hz}, 21 \mathrm{~Hz}, 22 \mathrm{~Hz}, 23 \mathrm{~Hz}$. Phase shift $\phi$ was assumed to be $0^{\circ}$ and $90^{\circ}$. 
After performing static structural modifications to the building construction (installation of HEA 300 and 200 elements) the dynamic response of the building structure's vibrations decreased by approximately $36 \%$.

\subsection{Results of the dynamic response of the steel ceiling structure}

Vertical vibrations of ceiling structures with large spans $(\geq 5 \mathrm{~m})$ degrade a person's sense of comfort. Movements of $2 \mathrm{~Hz}$ to $35 \mathrm{~Hz}$ are caused by a variety of mechanical devices, or by the movement of people.

To assess the dynamic flexibility of the ceiling structure we use the ratio of the speed of movement of the harmonic excitation force.

This ratio is also a function of damping vibration of the structure, which depends not only on the system and construction materials, but also on the degree of occupancy of rooms.

According to the measured results of the reinforced concrete ceiling construction with spans of $5 \mathrm{~m}$ to $10 \mathrm{~m}$, the maximum deflection peaks in the range of $10^{-5}$ to $10^{-6}\left(\mathrm{~ms}^{-1} \cdot \mathrm{N}^{-1}\right)$.

Critical peak values of deflection according to the standards stipulate a range of 0.00001 $-0.000001 \mathrm{~ms}^{-1} \cdot \mathrm{N}^{-1}$.

The deflection was calculated for the ceilings original condition (year 2013), where RMS vibration velocities measured $3.0 \mathrm{~mm} \cdot \mathrm{s}^{-1}$ and the amplitude of the harmonic excitation variable force is $200 \mathrm{~N}$.

The calculated ceiling deflection is $0.000015 \mathrm{~ms}^{-1} \cdot \mathrm{N}^{-1}$ and lies at the threshold permitted by relevant standards.

Fig. 6 shows experimentally observed frequency spectra of the vibration velocity of the building structure at selected measuring points obtained in 2013, prior to structural modifications of the ceiling structure.

Deflections were calculated for the structurally modified ceiling where RMS vibration velocity is $1.9 \mathrm{~mm} \cdot \mathrm{s}^{-1}$ and the amplitude of the harmonic excitation variable force is $200 \mathrm{~N}$.

The calculated deflection of the ceiling is 0.0000095 , which is the value of deflection located outside the limit range permitted by standards.

The post dynamic response of the structure exhibited a $36 \%$ reduction in deflection.

a) beam HEA 340, at the mid-span of the beam, point

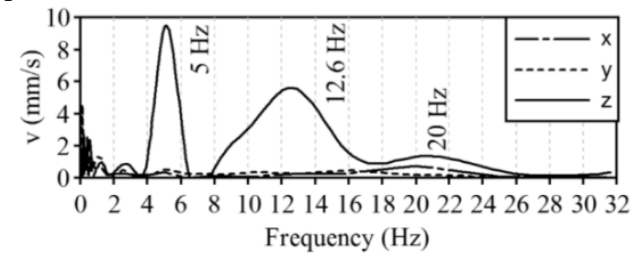

b) beam HEA 200, at the mid-span of the beam, point

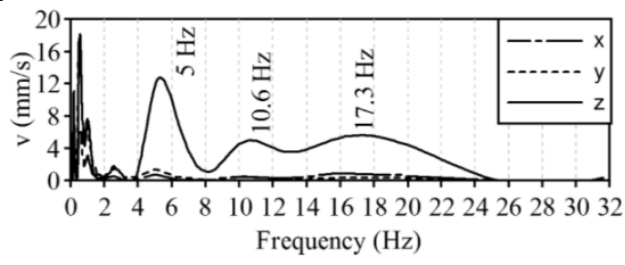

c) sheet, point 4

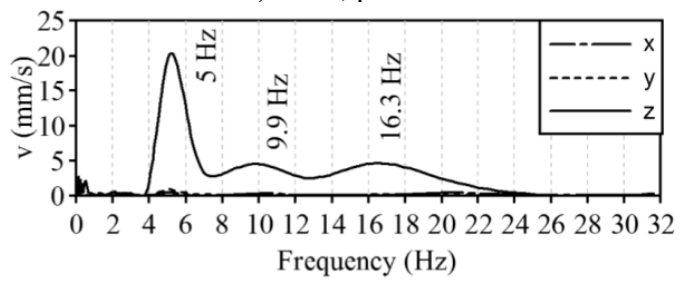

Fig. 6. Experimental power spectral density vibration rate of the building structure at selected measurement points, prior to structural modifications of the ceiling (original condition), year 2013. 


\section{Conclusions}

Based on a geodetic measurement of the deformation of steel elements supporting the ceiling, it was found that the maximum observed vertical deflection $(22 \mathrm{~mm})$ does not exceed that stipulated by standard STN EN 1993-1-1 Eurocode 3 permissible maximum vertical deflection (36 mm), i.e. structural steel ceiling in II limit terms (Serviceability limit state-SLS).

SLS assessment of the permissible maximum vertical deformation is suitable and the steel beam ceiling lies in the elastic range.

The magnetic particle test of the welds and bolts in selected locations revealed that the welds and bolts do not exhibit cracks and remain intact. Some welds were not properly executed, are intermittent or do not meet the standards stipulated by STN EN 17638 and evaluation EN ISO 5817. However, the current state of the welds does not significantly affect the carrying capacity of the building structure.

Experimental vibration measurements at selected points of the steel ceiling support structure in the dynamic response frequency spectrum showed a dominant frequency range between $6 \mathrm{~Hz}$ to $13 \mathrm{~Hz}$ and $19 \mathrm{~Hz}$ to $25 \mathrm{~Hz}$.

By comparing the experimentally measured frequency spectra dynamic response of the steel ceiling structure in 2015 with theoretically calculated values for the calculation model and experimentally measured frequency of the spectra dynamic response of the steel ceiling structure in 2013 it can be stated that dominant frequencies of vibration are diminished and shifted to a lower frequency range.

Based on the results and knowledge obtained it can be stated that the structural steel ceiling of the factory building at a height of $+10.5 \mathrm{~m}$, is safe and stable and can serve its intended purpose (laboratory space designed for testing automatic washing machines) over the next two years.

The paper is carried out within the project No. 1/0129/20, partially founded by the Science Grant Agency of the Ministry of Education of Slovak Republic and the Slovak Academy of Sciences. This work was partially supported by the Slovak Research and Development Agency under the contract, APVV-15-0777.

\section{References}

1. M. Kasprišin, Geodetic Surveying of steel ceiling elements (ZEKA 2015)

2. EN 1993-1-1: Eurocode 3, 2005: Design of steel structures.

3. Š. Horban, Report on Non-destructive testing of welds (Nekom-NDT, 2015)

4. J. Li, J. Chen, Stochastic Dynamics of structures (John Wiley and Sons 2009)

5. E. Simiu, Chaotic Transitions in Deterministic and Stochastic Dynamical System. (Princeton University Press, Princeton an Oxford 2010) 